\title{
Alpha cell
}

National Diabetes Information Clearinghouse (NDIC)

\section{Definitions}

\section{Pancreas}

Defined by National Diabetes Information Clearinghouse (NDIC)

Hormone

Defined by National Diabetes Information Clearinghouse (NDIC)

\section{Blood glucose}

Defined by National Diabetes Information Clearinghouse (NDIC)

Liver

Defined by National Diabetes Information Clearinghouse (NDIC)

Glucose

Defined by National Diabetes Information Clearinghouse (NDIC)

\section{Source}

National Diabetes Information Clearinghouse (U.S.). (2009). The diabetes dictionary. [Bethesda, Md.]: U.S. Dept. of Health and Human Services, National Institutes of Health, National Institute of Diabetes and Digestive and Kidney Diseases, National Diabetes Information Clearinghouse.

A type of cell in the pancreas. Alpha cells make and release a hormone called glucagon. The body sends a signal to the alpha cells to make glucagon when blood glucose falls too low. Then glucagon reaches the liver, where it tells the liver to release glucose into the blood for energy. 